\title{
Technical Note: An X-ray absorption method for the identification of calcium phosphate species using peak-height ratios
}

\author{
J. F. Oxmann \\ Helmholtz Centre for Ocean Research Kiel, Marine Biogeochemistry, Kiel, Germany \\ Correspondence to: J. F. Oxmann (joxmann@geomar.de) \\ Received: 13 November 2013 - Published in Biogeosciences Discuss.: 28 November 2013 \\ Revised: 24 February 2014 - Accepted: 5 March 2014 - Published: 17 April 2014
}

\begin{abstract}
X-ray absorption near edge structure (XANES) studies on calcium phosphate species (Ca-P) deal with marginal differences among subtle spectral features despite a hitherto missing systematic breakdown of these differences. Related fingerprinting approaches depend, therefore, on spectral libraries that are not validated against each other, incomplete and scattered among publications. This study compiled a comprehensive spectral library from published reference compound libraries in order to establish more clear-cut criteria for $\mathrm{Ca}-\mathrm{P}$ determination by distinctive phosphorus K-edge XANES features. A specifically developed normalization method identified diagnostic spectral features in the compiled library, e.g. by uniform calculation of ratios between white-line and secondary peak heights. Postprocessing of the spectra $(n=81)$ verified distinguishability among most but not all phases, which included hydroxylapatite (HAP), poorly crystalline HAP, amorphous HAP, fluorapatite, carbonate fluorapatite (CFAP), carbonate hydroxylapatite, $\beta$-tricalcium phosphate, octacalcium phosphate (OCP), brushite, monetite, monocalcium phosphate, amorphous calcium phosphate (ACP), anapaite, herderite, scholzite, messelite, whiteite and $\mathrm{P}$ on $\mathrm{CaCO}_{3}$. Particularly, peak-height ratios significantly improved analyte specificity, e.g. by supplementary breakdown into OCP and ACP. The spectral analysis also revealed Ca-P standards that were rarely investigated or inappropriately synthesized, and thus provides a basis for standard selection and synthesis. The method developed and resulting breakdown by species were subsequently tested on $\mathrm{Ca}-\mathrm{P}$ spectra from studies on bone and sediment. The test indicated that bone material likely comprises only poorly crystalline apatite, which confirms direct nucleation of apatite in bone. This biological apatite formation is likely opposed to that of sedimentary apatite, which apparently forms by both
\end{abstract}

direct nucleation and successive crystallization. Application of the method to $\mu$ XANES spectra of sediment particles indicated authigenic apatite formation by an OCP precursor.

\section{Introduction}

Calcium phosphates (Ca-P) are a group of several mineral species that are present in various biological and environmental matrices, such as soil, sediment, ores, fertilizers, agroindustrial by-products, milk, bone and tooth enamel. However, speciation techniques are not yet fully capable of unequivocally identifying certain key species due to sensitivity and specificity issues and the complexity of biological or environmental samples. Moreover, some Ca-P species form naturally occurring polymorphs, which further increases the number of target phases. An important example for this polymorphism is apatite that may occur in amorphous (e.g. bone apatite), cryptocrystalline (e.g. collophane) or crystalline (e.g. igneous apatite) forms.

A central research focus of studies on $\mathrm{Ca}-\mathrm{P}$ relates to natural formation processes of corresponding species, in particular of their end-members. The most common Ca-P endmembers in biological or environmental systems are species of the apatite group. For instance, authigenically formed carbonate fluorapatite (CFAP) is suggested to be a primary sink of reactive phosphorus (P) in the ocean (Ruttenberg, 1992; Ruttenberg and Berner, 1993) and thus a key compound during the ultimate stage of a complex P-removal mechanism in the global P cycle. It is thus distinguished from detrital fluorapatite (FAP), which is delivered to marine environments by continental weathering. Due to their occurrence in P-bearing rocks, apatites mark also the initial stage of $\mathrm{P}$ transformations 
in the global P cycle. Weathering of these rocks by soil genesis generates soluble $\mathrm{P}$, which then becomes available for biotic and abiotic P-transformation mechanisms (GiguetCovex et al., 2013).

Species of the apatite group may nucleate directly or form by transformation of previously precipitated metastable precursors (successive crystallization), such as octacalcium phosphate (OCP), amorphous calcium phosphate (ACP), brushite (DCPD; dibasic calcium phosphate dihydrate) and $\beta$-tricalcium phosphate ( $\beta$-TCP). Natural transformations among these $\mathrm{P}$ compounds are generally driven by both thermodynamic and kinetic factors. In simplified terms, thermodynamically less stable but rapidly precipitating Ca-P species may allow for successive crystallization pathways until the thermodynamically favoured but kinetically slow end-member formation occurs. Direct nucleation of apatite or transformation of precursors to apatite can also be inhibited or slowed, for example by $\mathrm{Mg}^{2+}$ ions in biological matrices and marine environments (Ban et al., 1993; Golubev et al., 1999; Gunnars et al., 2004; Martens and Harriss, 1970). The initial phase during apatite formation, including possible effects of precursors, has been primarily investigated with regard to bone apatite and marine CFAP-bearing phosphorite deposits but this subject still remains controversial (e.g. Atlas and Pytkowicz, 1977; Baturin, 1981; Bentor, 1980; Rey et al., 2009; Sheldon, 1981). This has been due largely to the above-mentioned difficulties in identifying $\mathrm{Ca}-\mathrm{P}$ within corresponding sample matrices down to species level. A brief description of the two major techniques for Ca-P determination in such matrices follows.

The conventional way to quantify the complete fraction of matrix-enclosed Ca-P is to perform sequential chemical extraction methods. Initial procedures were developed for soil, then adapted for sediment and more recently also employed for other matrices, such as agroindustrial by-products (e.g. Kruse et al., 2010). Advancements also facilitated separate quantification of FAP, CFAP, OCP and biogenic apatite (Oxmann and Schwendenmann, 2014; Ruttenberg, 1992; Schenau and De Lange, 2000). A major advantage of these procedures is their high sensitivity, which allows quantifications even in extremely P-poor environmental samples. However, the analyte specificity is limited and requires thorough verification because chemical extracts just provide operationally defined quantities.

In recent years, these extraction methods were applied together with X-ray absorption near edge structure spectroscopy (XANES) at the P K-edge (Beauchemin et al., 2003; Kruse and Leinweber, 2008; Kruse et al., 2010; Seiter et al., 2008; Shober et al., 2006; Toor et al., 2005). The relatively novel P K-edge XANES technique makes use of X-ray absorption by $\mathrm{P}$ atoms of a sample (for an introduction to the fundamental theory see, e.g., Newville, 2004). In brief, core shell electrons of these $\mathrm{P}$ atoms can be ejected from their quantum level thereby leaving core holes behind if their binding energies are lower than energies of incident X-rays. If this occurs, energies in excess of the binding energies are released by the emission of photoelectrons and the corresponding $\mathrm{P}$ atoms are in a so-called excited state. Next, the excited state may decay by a higher shell electron dropping into the core hole, which is accompanied by measurable emission of a fluorescence photon or measurable emission of another electron (termed Auger electron) into the continuum. Spectra obtained by these two emissions indicate the fluorescence yield (FY) or total electron yield (TEY) as a function of energy. In summary, the measured fluorescence intensity or electron yield is proportional to the absorption probability and a drop from an L-shell into a deeper K-shell by a prior absorption event causes measurable emissions at the absorption edge of the K-shell (Newville, 2004). This specific absorption edge is termed $\mathrm{K}$-edge and corresponding XANES measurements provide spectra of the energy region near the K-edge. Equivalent analyses of environmental samples at the P L-edge or at extended regions of the $\mathrm{K}$-edge (extended $\mathrm{X}$-ray absorption fine-structure spectroscopy) currently have a limited application range due to their comparatively low sensitivity (Toor et al., 2006).

As the X-ray absorption probability depends on the chemical and physical state of an atom and its surroundings, XANES generally provides the capability to distinguish among crystalline Ca-P species. Moreover, XANES requires minimal sample preparation and is apparently not or only minimally affected by common sample matrices. Unlike most other structural probes it is also capable of providing analysable signals of amorphous compounds (Newville, 2004). However, quantification of matrix-enclosed Ca-P species by XANES is currently restricted because quantitative XANES probes all $\mathrm{P}$ atoms within a sample. Hence, different species contribute to the measured spectrum, which is problematic because their spectral features overlap (Doolette and Smernik, 2011). Despite approaches to tackling this issue by least-squares linear combination fitting or principal component analysis with target transformation (Ajiboye et al., 2007b; Beauchemin et al., 2003, and references therein), it has been therefore recommended to use XANES together with sequential extraction methods (Ajiboye et al., 2007a, 2008; Kruse and Leinweber, 2008). Fortunately, inevitable merging of spectra by bulk XANES analysis can be overcome by resolving particular species within individual matrix particles using a focused beam at sub-micron spatial resolution ( $\mu$ XANES; e.g. Brandes et al., 2007). Although $\mu X A N E S$ is not quantitative, it provides a more straightforward approach to ensuring that apparent compositions of bulk XANES analyses represent actual compositions.

Applications of these two XANES techniques are at present mainly based on fingerprinting approaches because $\mathrm{ab}$ initio fitting of corresponding spectra is currently impaired by the complex theory behind XANES-typical multiple scattering regimes. As P K-edge XANES approaches therefore rely on a comparison between samples and reference materials, the analyte specificity depends on the 
degree of conformity between the species of a sample and reference species as well as on measurement reproducibility (e.g. Giguet-Covex et al., 2013). Due to variability among XANES measurements, for instance by differing energy calibrations, self-absorption and particle size effects, P XANES fingerprinting approaches include their own spectral libraries of apparently best suited reference species. Because of timeconsuming acquisition and synthesis of reliable reference compounds and specifically due to the temporary use of synchrotron facilities, these libraries usually encompass projectoriented and, consequently, incomplete subsets of spectra. Further, verification of synthesized reference compounds is difficult because these libraries are not systematically validated against each other. Finally, spectra of different Ca-P species show just marginal differences among subtle spectral features and the compatibility of two spectra is often deduced from apparent conformities among those subtle features. Due to the lack of a systematic spectral comparison, clear-cut criteria for the identification of $\mathrm{Ca}-\mathrm{P}$ species are not available to date.

Hence, the study objectives were (i) to establish a spectral library that encompasses a compiled suite of P K-edge XANES spectra of various Ca-P species published in the literature; and (ii) to conduct a systematic comparison of spectra included in this library in order to identify diagnostic spectral features. An insightful comparison was achieved by a specifically developed normalization method that identified subtle but distinctive spectral disparities for the differentiation of calcium phosphate species.

\section{Methods}

\subsection{Collection of P K-edge XANES spectra}

Phosphorus K-edge XANES spectra of Ca-P reference compounds were collected from literature resources that included corresponding spectral libraries (Table 1; 17 libraries). The majority of these libraries ( $n=13)$ were drawn from a comprehensive compilation of XANES studies published in a review of spectroscopic approaches for $\mathrm{P}$ speciation in environmental matrices (Kizewski et al., 2011) and were assumed to be representative of common measurement variations. Libraries of these studies were selected if they comprised more than one species for $\mathrm{Ca}-\mathrm{P}$ and sufficient energy ranges from white-line peaks to oxygen oscillations. One exception was the study of Beauchemin et al. (2003), whose library did not include oxygen oscillations, yet contained a valuable set of reference compounds. As the method developed generally required spectral coverage of oxygen oscillations (see Sect. 2.2), spectra of Beauchemin et al. (2003) were consequently processed by an additional alignment with other spectra. Potential duplicates were excluded, such as spectra of Lombi at al. (2006). Their study comprised personally supplied spectra of researchers, who collected spectra already selected for the systematic comparison (Hesterberg et al., 1999; Peak et al., 2002). Additional libraries of four other studies were included, all but one of which were from the period between the review of Kizewski et al. (2011) and the collection of spectra for the systematic comparison (see bold reference numbers in Table 1). Plot data were retrieved by optical plot reading using a line-following routine (OPR; CurveSnap V1.0) and subsequently post-processed using a spreadsheet application (see Sect. 2.2).

The compiled library (Table 1) comprised 76 spectra of reference compounds, which included spectra of hydroxylapatite (HAP), poorly crystalline HAP, amorphous HAP, FAP, CFAP, carbonate hydroxylapatite (CHAP), $\beta$-TCP, OCP, DCPD, monetite (DCPA), monocalcium phosphate (MCP), $\mathrm{ACP}$ and $\mathrm{P}$ on $\mathrm{CaCO}_{3}$. Five additional spectra of anapaite, herderite, scholzite, messelite and whiteite (Ingall et al., 2011) were used for a more general comparison but excluded from a detailed analysis due to their unusual and easily distinguishable spectral features. In addition to the above-mentioned reference compounds, the library also included Ca-P of two sediment particles (Brandes et al., 2007; not listed in Table 1) and six bone apatites (deer, sheep, chamois, chicken, pig, bovine; Rajendran, 2011; Rajendran et al., 2013; not listed in Table 1). Most original spectra were already normalized by subtracting a linear regression function for the pre-edge region and fitting the post-edge region to a quadratic polynomial function. However, all data were post-processed by a uniform procedure in order to standardize retrieved spectra.

\subsection{Post-processing of P K-edge XANES spectra}

A specific absorbance and energy normalization procedure was applied to all spectra for a preliminary spectral comparison and a subsequent determination of peak-height ratios and relative peak positions (Fig. 1a). Absorbance was scaled relative to a unit edge jump at $2180 \mathrm{eV}$ and energy normalized by adjusting main (white-line) peaks to $2150 \mathrm{eV}$ and tertiary peaks (oxygen oscillations) to ca. $2167 \mathrm{eV}$. To energynormalize the spectra, most distant features were used, that is, the white-line peak and the oxygen oscillation. The adjustment of white-line peaks to $2150 \mathrm{mV}$ was very precise due to relatively thin and intense peaks (Figs. 1a and 3). In the case of less precisely definable centre positions of tertiary peaks (see, e.g., flattened peak of the oxygen oscillation of HAP-4 in Fig. 1a), the normalization was optimized by also matching the secondary peak of such a spectrum to the range of secondary peaks of spectra belonging to the same species (see secondary peak of HAP-4 in Fig. 1a). However, the energy normalization was always conducted by means of a suitable normalization factor, which was applied to the spectral range investigated. Energy normalization standardized differing spectra with respect to their white lines and oxygen oscillations and therefore accounted for species-specific secondary peak positions relative to white 
Table 1. Compiled library of P K-edge XANES spectra for calcium phosphate standards.

\begin{tabular}{|c|c|c|c|c|c|}
\hline Calcium phosphate & Mode & Type & Reference for synthesis or source; [deposit] & No. & Reference \\
\hline HAP-1 & FY & $\mathrm{N}$ & Excalibur Mineral; [Snarum, Norway] & 1 & Brandes et al. (2007) \\
\hline HAP-2 & FY & $\mathrm{S}$ & Fisher Scientific & 2 & Shober et al. (2006) \\
\hline HAP-3 & TEY & N/A & N/A & 3 & Rajendran et al. (2013) \\
\hline HAP-4 & FY & $\mathrm{S}$ & Fisher Scientific & 4 & Peak et al. (2002) \\
\hline HAP-5 & FY & $\mathrm{N}$ & National Museum of Natural History, France; [N/A] & 5 & Giguet-Covex et al. (2013) \\
\hline HAP-6 & FY & N/A & N/A & 6 & Eveborn et al. (2009) \\
\hline HAP-7 & TEY & $\mathrm{S}$ & Clarkson Chromatography Products Inc. & 7 & Güngör et al. (2007) \\
\hline HAP-8 & FY & $\mathrm{S}$ & Sigma Aldrich & 8 & Hesterberg et al. (1999) \\
\hline HAP-9 & FY & $\mathrm{S}$ & Sigma Aldrich & 9 & Sato et al. (2005) \\
\hline HAP-10 & FY & $\mathrm{N}$ & Tennessee Valley Authority; [N/A] & 9 & Sato et al. (2005) \\
\hline HAP-11 & FY & $\mathrm{N}$ & Univ. of Greifswald; [Ehrenfriedersdorf, Germany] & 10 & Kruse and Leinweber (2008) \\
\hline HAP-12 & FY & SDS & Brandes et al. (2007) & 11 & Diaz et al. (2008) \\
\hline HAP- 13 & FY & $\mathrm{S}$ & Chemical supply company & 13 & Ajiboye et al. (2008) \\
\hline HAP-14 & FY & $\mathrm{S}$ & Chemical supply company & 15 & Beauchemin et al. (2003) \\
\hline HAP-15 & FY & N/A & N/A & 16 & Toor et al. (2006) \\
\hline HAP-16 & FY & $\mathrm{S}$ & Sigma Aldrich & 17 & Kruse et al. (2010) \\
\hline HAP-17 (chlorian) & FY & $\mathrm{N}$ & Mineral dealer; [Bamle, Norway] & 12 & Ingall et al. (2011) \\
\hline OCP-1 & FY & $\mathrm{S}$ & Christoffersen et al. (1990) & 2 & Shober et al. (2006) \\
\hline OCP-2 & FY & $\mathrm{S}$ & Christoffersen et al. (1990) & 6 & Eveborn et al. (2009) \\
\hline OCP-3 & TEY & $\mathrm{S}$ & Clarkson Chromatography Products Inc. & 7 & Güngör et al. (2007) \\
\hline OCP-4 & FY & $\mathrm{S}$ & Christoffersen et al. (1990) & 8 & Hesterberg et al. (1999) \\
\hline OCP-5 & FY & $\mathrm{S}$ & Christoffersen et al. (1990) & 9 & Sato et al. (2005) \\
\hline OCP-6 & FY & $\mathrm{S}$ & Arellano-Jiménez et al. (2009) & 5 & Giguet-Covex et al. (2013) \\
\hline OCP-7 & FY & $\mathrm{S}$ & Christoffersen et al. (1989) & 15 & Beauchemin et al. (2003) \\
\hline OCP-8 & FY & S & Christoffersen et al. (1990) & 17 & Kruse et al. (2010) \\
\hline FAP-1 & FY & $\mathrm{N}$ & Excalibur Mineral; [Durango, Mexico] & 1 & Brandes et al. (2007) \\
\hline FAP-2 & FY & $\mathrm{N}$ & Mineral dealer; [Beartooth Mountains, USA] & 12 & Ingall et al. (2011) \\
\hline FAP-3 & FY & $\mathrm{N}$ & Mineral dealer; [Conda, USA] & 12 & Ingall et al. (2011) \\
\hline FAP-4 & FY & $\mathrm{N}$ & Mineral dealer; [Conselheiro Pena, Brazil] & 12 & Ingall et al. (2011) \\
\hline FAP-5 & FY & $\mathrm{N}$ & Mineral dealer; [Ipira, Brazil] & 12 & Ingall et al. (2011) \\
\hline FAP-6 & FY & $\mathrm{N}$ & Mineral dealer; [Renfrew County, Canada] & 12 & Ingall et al. (2011) \\
\hline FAP-7 & FY & $\mathrm{N}$ & Mineral dealer; [Durango, Mexico] & 12 & Ingall et al. (2011) \\
\hline FAP-8 & FY & N/A & N/A & 16 & Toor et al. (2006) \\
\hline CHAP fluorian & FY & $\mathrm{N}$ & Mineral dealer; [Snarum, Norway] & 12 & Ingall et al. (2011) \\
\hline CFAP-1 & FY & $\mathrm{N}$ & Mineral dealer; [Brewster, FL, USA] & 12 & Ingall et al. (2011) \\
\hline CFAP-2 & FY & $\mathrm{N}$ & Mineral dealer; [St Just, England] & 12 & Ingall et al. (2011) \\
\hline CFAP-3 & FY & $\mathrm{N}$ & Mineral dealer; [Stoke Climstand, England] & 12 & Ingall et al. (2011) \\
\hline CFAP-4 & FY & SDS & Brandes et al. (2007) & 11 & Diaz et al. (2008) \\
\hline CFAP-5 & FY & SDS & Brandes et al. (2007) & 11 & Diaz et al. (2008) \\
\hline$\beta-\mathrm{TCP}-1$ & FY & $\mathrm{S}$ & Kwon et al. (2003) & 2 & Shober et al. (2006) \\
\hline$\beta-\mathrm{TCP}-2$ & TEY & N/A & N/A & 3 & Rajendran et al. (2013) \\
\hline$\beta-\mathrm{TCP}-3$ & TEY & $\mathrm{S}$ & HiMed Bioactive Materials Resource Center & 7 & Güngör et al. (2007) \\
\hline$\beta-\mathrm{TCP}-4$ & FY & $S$ & Sigma Aldrich & 9 & Sato et al. (2005) \\
\hline ACP-1 & FY & $\mathrm{S}$ & Own procedure & 6 & Eveborn et al. (2009) \\
\hline ACP-2 & TEY & $\mathrm{S}$ & HiMed Bioactive Materials Resource Center & 7 & Güngör et al. (2007) \\
\hline$A C P-3$ & $F Y$ & $S$ & Christoffersen et al. (1990) & 9 & Sato et al. (2005) \\
\hline$A C P-4$ & $F Y$ & $S$ & Christoffersen et al. (1990) & 9 & Sato et al. (2005) \\
\hline
\end{tabular}


Table 1. Continued.

\begin{tabular}{|c|c|c|c|c|c|}
\hline Calcium phosphate & Mode & Type & Reference for synthesis or source; [deposit] & No. & Reference \\
\hline DCPD-1 & FY & N/A & N/A & 6 & Eveborn et al. (2009) \\
\hline DCPD-2 & TEY & $\mathrm{S}$ & Clarkson Chromatography Products Inc. & 7 & Güngör et al. (2007) \\
\hline DCPD-3 & FY & $\mathrm{S}$ & Sigma Aldrich & 8 & Hesterberg et al. (1999) \\
\hline DCPD-4 & FY & $\mathrm{S}$ & Sigma Aldrich & 9 & Sato et al. (2005) \\
\hline DCPD-5 & FY & $\mathrm{S}$ & Sigma Aldrich & 10 & Kruse and Leinweber (2008) \\
\hline DCPD-6 & FY & $\mathrm{S}$ & Fisher Scientific & 2 & Shober et al. (2006) \\
\hline DCPD-7 & FY & $\mathrm{S}$ & Chemical supply company & 13 & Ajiboye et al. (2008) \\
\hline DCPD-8 & FY & $\mathrm{S}$ & Chemical supply company & 14 & Ajiboye et al. (2007) \\
\hline DCPD-9 & FY & N/A & N/A & 16 & Toor et al. (2006) \\
\hline DCPA-1 & FY & $\mathrm{N}$ & Non-commercial source; [N/A] & 4 & Peak et al. (2002) \\
\hline DCPA-2 & FY & N/A & N/A & 6 & Eveborn et al. (2009) \\
\hline DCPA-3 & TEY & S & Clarkson Chromatography Products Inc. & 7 & Güngör et al. (2007) \\
\hline DCPA-4 & FY & $\mathrm{S}$ & Sigma Aldrich & 8 & Hesterberg et al. (1999) \\
\hline DCPA-5 & FY & $\mathrm{S}$ & Sigma Aldrich & 9 & Sato et al. (2005) \\
\hline DCPA-6 & TEY & N/A & N/A & 3 & Rajendran et al. (2013) \\
\hline DCPA-7 & FY & $S$ & J.T. Baker & 2 & Shober et al. (2006) \\
\hline DCPA-8 & FY & $\mathrm{S}$ & Chemical supply company & 12 & Ingall et al. (2011) \\
\hline DCPA-9 & FY & $\mathrm{S}$ & Chemical supply company & 13 & Ajiboye et al. (2008) \\
\hline DCPA-10 & FY & $\mathrm{S}$ & Chemical supply company & 15 & Beauchemin et al. (2003) \\
\hline DCPA-11 & FY & N/A & N/A & 16 & Toor et al. (2006) \\
\hline DCPA-12 & FY & N/A & N/A & 16 & Toor et al. (2006) \\
\hline DCPA-13 & TEY & N/A & N/A & 16 & Toor et al. (2006) \\
\hline MCP-1 & FY & $\mathrm{S}$ & Sigma Aldrich & 10 & Kruse and Leinweber (2008) \\
\hline MCP-2 & TEY & N/A & N/A & 3 & Rajendran et al. (2013) \\
\hline MCP-3 & FY & $\mathrm{S}$ & Sigma Aldrich & 2 & Shober et al. (2006) \\
\hline $\mathrm{P}$ on $\mathrm{CaCO}_{3}-1$ & FY & $\mathrm{S}$ & Own procedure & 5 & Giguet-Covex et al. (2013) \\
\hline $\mathrm{P}$ on $\mathrm{CaCO}_{3}-2$ & FY & N/A & N/A & 4 & Peak et al. (2002) \\
\hline Amorphous HAP & FY & N/A & N/A & 4 & Peak et al. (2002) \\
\hline Poorly cryst. HAP & FY & $\mathrm{N}$ & Mineral dealer; [Mono Lake, USA] & 12 & Ingall et al. (2011) \\
\hline
\end{tabular}

FY, TEY: fluorescence yield, total electron yield; S, N, N/A: synthetic, natural, not available; SDS: Secondary data source; italics: putative OCP-contaminated ACP; bold reference numbers: studies not included in Kizewski et al. (2011).

lines and oxygen oscillations. This procedure also allowed for an averaging of multiple spectra belonging to the same $\mathrm{P}$ species and setting peak baselines for all spectra at equal energies. For a more general comparison of species-specific spectral features (Sect. 3.2; Fig. 2), absorbance was normalized to go from 0 to 1 at the energy of the maximum first derivative (threshold energy; see Newville, 2004). The normalized spectra thus obtained were subsequently averaged for each species.

In order to determine main and secondary peak heights and relative peak positions, uniform baselines were operationally defined across all energy-normalized spectra by linear fits between energies of 2147.05, 2156.4, 2158.25 and $2162.2 \mathrm{eV}$ (Fig. 1a) and subsequently subtracted (Fig. 1b). The baseline-subtracted spectra were again scaled relative to maximum main peak intensities of one (or 100\%) and then averaged for each species. This final normalization was employed to visualize differences among peak intensity ratios (secondary peak heights relative to white-line peak heights) for the reference compounds analysed (Figs. 3 and 4). It is important to note that absorbance normalizations did not affect determined peak-height ratios. Thus, only the initial energy normalization influenced species-specific peak-height ratios due to the adjustment of the spectra relative to fixed baseline positions. Additional post-edge background subtraction was omitted due to the limited energy range of most available spectra. Peak-height ratios between main and secondary peaks (see A and B in Fig. 1a, b) were expressed as relative secondary peak heights (arbitrary units relative to maximum main peak intensities of one or percentages of main peak heights). All curves were slightly smoothed by a cubic B-spline connection. B-splines, baseline subtractions, peak positions, peak heights and averages of multiple curves were calculated using the data analysis program OriginPro 7.5 (OriginLab Corp., USA). Quality of OPR was verified by performing the above-mentioned analytical procedure for both available primary data and corresponding digitized plot data (see Fig. S1 in the Supplement). The correlation 


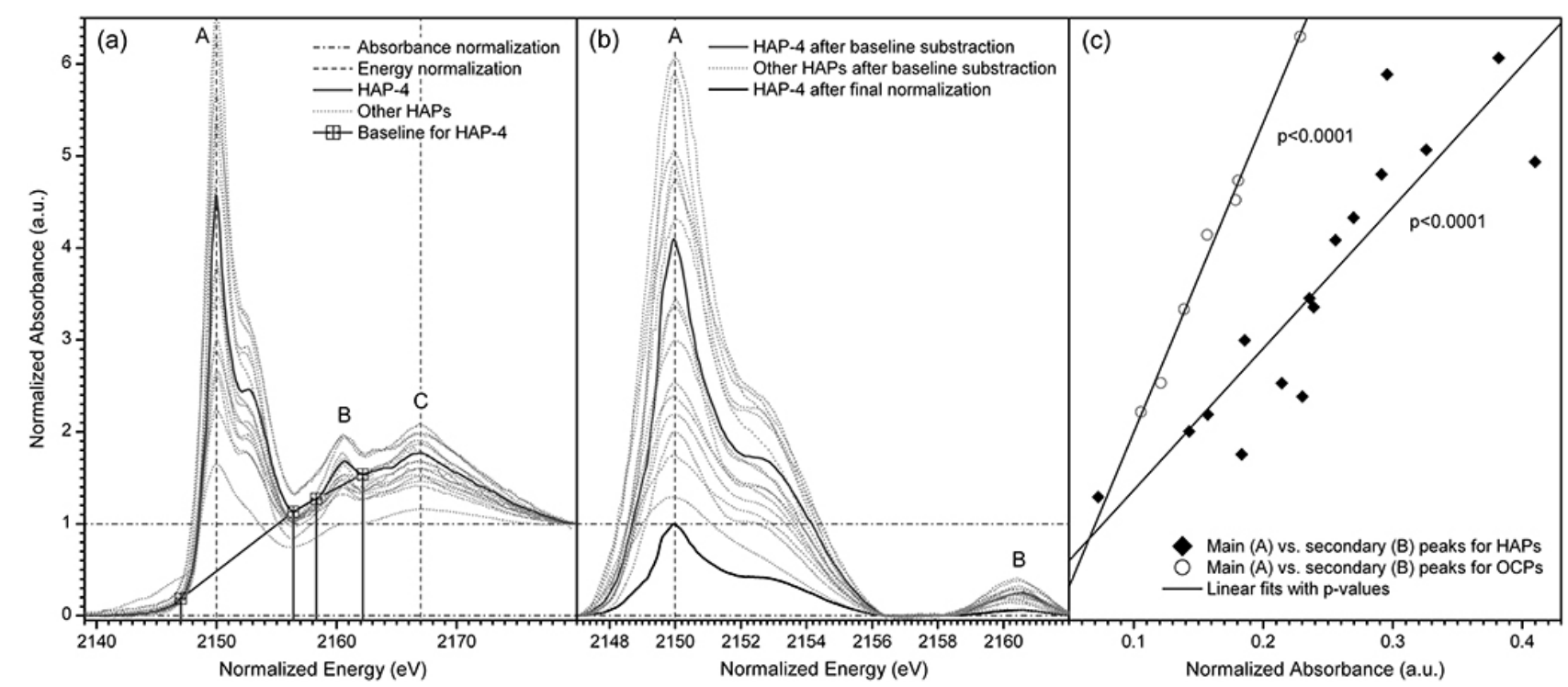

Fig. 1. Normalization procedure for collected P K-edge XANES spectra as exemplified for HAP-4 and other HAP reference materials. (a) Initial absorbance and energy normalization by adjusting absorbance to a unit edge jump at $2180 \mathrm{eV}$, main peaks (A) to $2150 \mathrm{eV}$ and tertiary peaks (C) to ca. $2167 \mathrm{eV}$. Baselines for all spectra were operationally defined by linear fits between normalized energies of 2147.05 , 2156.4, 2158.25 and $2162.2 \mathrm{eV}$. (b) Spectra after baseline subtraction. These baseline-subtracted spectra were finally scaled relative to maximum main peak intensities of one (see final normalization for HAP-4) to visualize differences among peak intensity ratios (A/B) for reference compounds analysed (Fig. 3). (c) As indicated for HAP and OCP reference materials, peak intensities of main (A) and secondary (B) peaks were linearly correlated. Resulting intensity ratios identified species-specific fingerprints (Figs. 3 and 4). See Table 1 for analyte properties.

between results of these two input data types was highly significant $(r=0.99 ; p<0.0001)$.

\section{Results and discussion}

\subsection{Spectral library}

Among the 76 spectra of the compiled library (Table 1), HAP had the highest number of available spectra $(n=17)$, followed by DCPA ( $n=13), \mathrm{DCPD}(n=9), \mathrm{FAP}(n=8)$, OCP $(n=8)$, carbonated apatites $(n=6), \beta$-TCP $(n=4)$, ACP $(n=4)$, MCP $(n=3), P$ on $\mathrm{CaCO}_{3}(n=2)$, amorphous $\operatorname{HAP}(n=1)$ and poorly crystalline HAP $(n=1)$. As most of the different spectra for certain particular species were similar, representative model spectra were obtained by averaging multiple curves. Additionally, five easily distinguishable standard spectra of non-apatitic Ca-P compounds (anapaite, herderite, scholzite, messelite, whiteite; Ingall et al., 2011) are shown for a more general comparison in Fig. 2.

The majority of reference materials were either selfsynthesized minerals or certified synthetic minerals of chemical supply companies. Fluorapatites and carbonated apatites were natural specimens acquired from mineral dealers. For HAP, the library included several spectra of natural and synthetic specimens, thereby facilitating a spectral comparison of both sources. Additional Ca-P spectra of sediment particles (Brandes et al., 2007) and bone apatites (Rajendran,
2011; Rajendran et al., 2013) demonstrated the capability of the developed normalization method for determining particular Ca-P minerals in sample matrices (see Sect. 3.4).

Despite certain advantages, such as surface-sensitivity and prevention of self-absorption, spectra collected were rarely obtained by measuring the intensity of emitted electrons (TEY; Table 1). Most spectra were collected in fluorescence mode and most procedures describe measures taken to reduce self-absorption (e.g. using diluted or finely ground and thinly mounted samples) or to correct data by appropriate equations. One advantage of FY spectra is their occasionally richer structure compared to TEY spectra (see Toor et al., 2006). However, spectra for certain species that were collected by both techniques yielded comparable results (see Sect. 3.5).

\subsection{General species-specific spectral features}

Despite several remaining technical issues with the relatively novel $\mathrm{P}$ speciation by XANES, spectra were in good agreement. Virtually all publications indicated comparable spectral features of mineral Ca-P at the $\mathrm{P}$ K-edge, which provided the opportunity to detect the abundance of this $\mathrm{P}$ fraction in complex matrices (see, e.g., Ca-P content in soil by XANES vs. chemical fractionation; Beauchemin et al., 2003; Kruse et al., 2010; Shober et al., 2006). These spectral features were distinctive and characterized by (i) a post-edge shoulder at the high-energy side of the main (white-line) peak, which is 

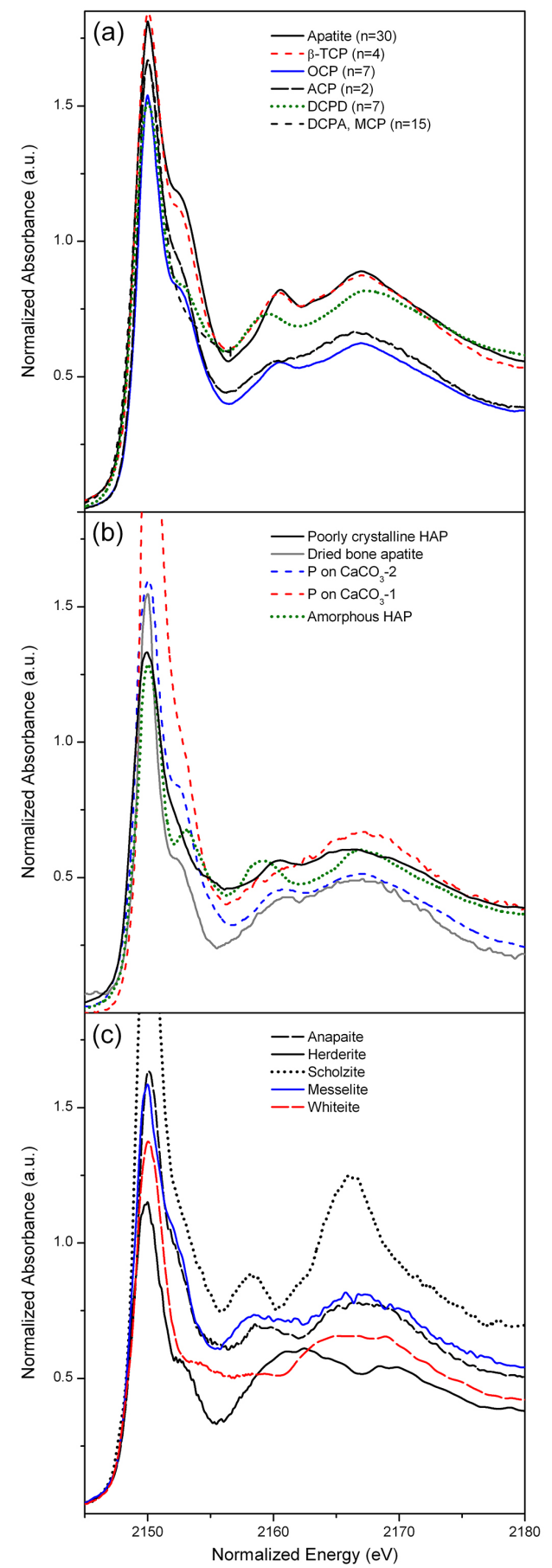

Fig. 2. First-derivative normalized P K-edge XANES spectra of $\mathrm{Ca}-\mathrm{P}$ reference compounds. (a) Averaged spectra for apatites, $\beta$-tricalcium phosphate ( $\beta$-TCP), octacalcium phosphate (OCP), amorphous calcium phosphate (ACP), brushite (DCPD), monetite (DCPA) and monocalcium phosphate (MCP). (b) Spectra for poorly crystalline and amorphous apatite, bone apatite and $\mathrm{P}$ adsorbed on $\mathrm{CaCO}_{3}$. (c) Spectra of different non-apatitic $\mathrm{Ca}-\mathrm{P}$ minerals (Ingall et al., 2011). Oxygen oscillations in (c) were not adjusted to ca. $2167 \mathrm{eV}$ due to unusual spectral features. located at about $2150 \mathrm{eV}$; (ii) an oxygen oscillation centred at about $17 \mathrm{eV}$ above the main peak; and (iii) a secondary peak between the main peak and the oxygen oscillation (Fig. 2a). Averaged spectra of apatite $(n=30), \beta$-TCP $(n=4)$, OCP $(n=7)$ and $\mathrm{ACP}(n=2)$ exhibited all three features, and the positions of secondary peaks between main peaks and oxygen oscillations were almost identical. The distance between main peaks and secondary peaks was larger (ca. $10 \mathrm{eV}$ ) than the distance between secondary peaks and oxygen oscillations (ca. $7 \mathrm{eV})$. For brushite $(n=7)$, all three features were also present but secondary peaks exhibited a slight shift towards main peaks. The spectra of monetite and MCP were comparable and displayed a lack of the post-edge shoulder (secondary peak and oxygen oscillation omitted in Fig. 2a for visual clarity). A few spectra of the reference library were excluded from averaging in Fig. 2a due to a limited energy range (spectra of Beauchemin et al., 2003) or inconsistency with common species-specific spectra (see explanations in Sect. 3.3).

Cryptocrystalline apatites and $\mathrm{P}$ adsorbed on $\mathrm{CaCO}_{3}$ were generally characterized by broadened peaks, particularly in terms of their oxygen oscillations (Fig. 2b). Co-precipitation is frequently an issue for the synthesis of $\mathrm{P}$ adsorbed on $\mathrm{CaCO}_{3}$. Thus, the line shape of spectra of adsorbed $\mathrm{P}$, which was comparable to those of poorly crystalline apatite or ACP, may be attributable to mineral Ca-P (Peak et al., 2002). Coprecipitation probably also affected the spectrum of amorphous apatite because it showed the brushite-typical secondary peak shift. Spectra of different additional non-apatitic Ca-P minerals (Ingall et al., 2011, Fig. 2c) were generally easily distinguishable from those of apatite, $\beta$-TCP, OCP, $\mathrm{ACP}$, brushite and monetite due to unusual features. These features included very broad secondary peaks and/or very broad oxygen oscillations for whiteite, herderite, anapaite and messelite and a comparatively high intensity of the oxygen oscillation for scholzite.

Differences among spectra of apatite, $\beta$-TCP, OCP and ACP were most difficult to unravel due to very similar centre positions and energy ranges of peaks (Fig. 2). In order to distinguish these spectra, it proved necessary to consider peak intensities. However, these intensities are frequently influenced by self-absorption and generally given as arbitrary units. To solve this problem, peak-height ratios between main and secondary peaks were analysed. Corresponding results are described in the following section.

\subsection{Species-specific peak-height ratios}

Ratios between main and secondary peaks indicated relatively high method specificity for the discrimination among certain species (Fig. 3). For all spectra analysed, the relative secondary peak heights of FAP, HAP, CFAP, CHAP and $\beta$ TCP were higher than those of OCP and ACP. Reference materials for DCPD generally showed OCP-typical secondary peak heights but their secondary peak positions were at lower 

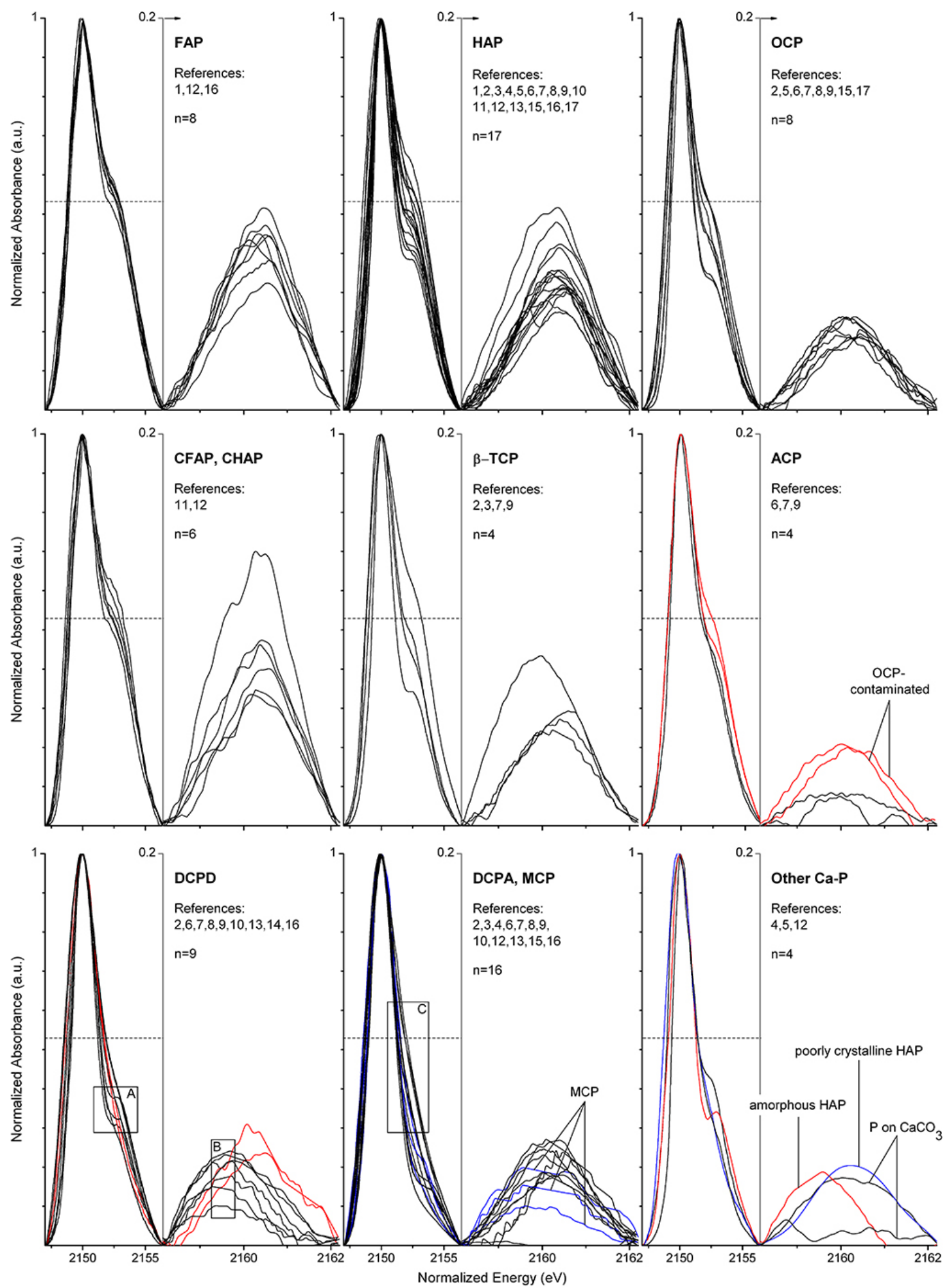

Fig. 3. Species-specific XANES fingerprints of $74 \mathrm{Ca}-\mathrm{P}$ reference compounds identified by normalized secondary peak positions and heights. Secondary peak heights are given as arbitrary units relative to maximum main peak intensities of one. Two ACPs likely contained OCP (red curves; text). DCPDs generally showed OCP-like secondary peak heights but their secondary peak positions were at lower energies (B). Two DCPDs with secondary peaks at higher energies (red curves; text) lack OCP-like post-edge shoulders (A). Secondary peaks of DCPAs and MCPs are comparable to those of OCPs, but their main peaks always lack typical post-edge shoulders (C). Reference numbers refer to detailed information in Table 1. Dotted lines indicate the average post-edge shoulder height of apatite $(n=30)$. 
energies, as described above. Two atypical DCPD spectra had secondary peaks at higher energies (red curves in DCPD plot; excluded from averaging in Fig. 2). These spectra were, however, still distinguishable from spectra of OCP because they lacked OCP-typical post-edge shoulders. Due to consistently absent post-edge shoulders, the spectra of DCPA and MCP were also different from OCP despite many OCPtypical secondary peaks of DCPA and MCP. Furthermore, spectra of reference materials for $\mathrm{P}$ adsorbed on $\mathrm{CaCO}_{3}$ and for amorphous and poorly crystalline HAP partly exhibited OCP-typical secondary peak heights but they showed other distinctive features, as described above. Therefore, the spectra of the 8 analysed OCP specimens were unique among the 81 analysed spectra of various Ca-P species, albeit with one probably insignificant restriction: two of the four ACP reference materials showed secondary peak heights that were comparable to those of OCP (red curves in ACP plot of Fig. 3; excluded from averaging in Fig. 2). However, Eveborn et al. (2009) noticed by ATR-FTIR (attenuated total reflectance Fourier-transform infrared spectroscopy) and XRPD (X-ray powder diffraction) analyses that the method suggested by Christoffersen et al. (1990) for synthesis of two ACP polymorphs (frequently referred to as ACP1 and ACP2) produced significant amounts of OCP. Yet the method of Christoffersen et al. (1990) was employed to synthesize samples for the two ACP spectra, which were comparable to those of OCP (Table 1, italics). Eveborn et al. (2009) subsequently developed their own procedure and the OCP-free sample produced generated a spectrum, which was comparable to that of an ACP reference material produced by a chemical supply company (HiMed Bioactive Materials Resource Center; Table 1; Güngör et al., 2007). These two reliable ACP spectra exhibited significantly lower secondary peak heights than all eight OCP spectra and were therefore easily distinguishable from OCP (Fig. 3). Finally, both of these reliable ACP spectra also showed a less pronounced shoulder, whereas spectra of the putatively OCP-contaminated ACP samples exhibited a larger OCP-like shoulder width (Fig. 3; see also discussion below). These results therefore strongly suggest that the reference materials for the two OCP-like ACP spectra were indeed OCP-contaminated and that particular care must be taken to avoid this contamination. Similar relative secondary peak heights of the eight OCP spectra indicated that OCP can be reliably synthesized using the procedures described (Table 1). Furthermore, these similar peak heights resulted in a relatively narrow secondary peak intensity range that did not overlap with that of apatite. All in all, then, OCP, ACP, DCPD and DCPA/MCP are likely distinguishable by $\mathrm{P}$ K-edge XANES using the proposed method that implements an analysis of peak-height ratios. Moreover, this method can also be applied to differentiate between these thermodynamically less stable Ca-P minerals and apatite or $\beta$-TCP.

As secondary peak intensity ranges of different spectra for FAP, HAP, CFAP, CHAP and $\beta$-TCP generally overlap, these compounds could not be separately identified by their relative secondary peak heights. However, results of a one-way analysis of variance revealed statistically significant differences between groups of these reference compounds in terms of relative secondary peak heights (FAP/CFAP/CHAP, HAP, $\beta$-TCP: $F(2,31)=6.10$, $p=0.0058$ ). Post hoc analyses indicated that the group of FAP, CFAP and CHAP had significantly higher normalized secondary peaks than HAP or $\beta$-TCP. Further, significant differences were detected between groups of apatite/ $\beta$ TCP, OCP, ACP, DCPD and DCPA/MCP in terms of relative secondary peak heights (FAP/HAP/CFAP/CHAP/BTCP, OCP, ACP, DCPD, DCPA/MCP: $F(4,62)=24.18$, $p<0.0001)$. Related post hoc analyses showed that the apatite/ß-TCP group had significantly higher secondary peaks compared to OCP, ACP, DCPD and DCPA/MCP. Averaged secondary peak heights were obtained from model spectra, which were created by averaging multiple normalized and baseline-subtracted spectra for each species (Fig. 4). These average heights (\% of white-line peak height; Fig. 4; Table 2) decreased in the following order: FAP $(8.5 \%)>$ carbonated apatites $(8 \%)>\mathrm{HAP}(7 \%)>\beta$-TCP $(5.9 \%)>$ OCP $(4 \%)>\operatorname{DCPD}(3.7 \%)>$ ACP $(1.6 \%)$. The averaged post-edge shoulder height (\% of main peak height; Fig. 4; Table 2) decreased in precisely the same sequence, and hence these two parameters were generally correlated (also for sets of reference compounds belonging to the same species; not shown), except for ACP. However, ACP showed a less pronounced post-edge shoulder when compared to the other species shown in Fig. 4.

Several authors commented that the post-edge shoulder appeared more well defined with increasing thermodynamic stability of the investigated Ca-P minerals (Ajiboye et al., 2008; Eveborn et al., 2009; Güngör et al., 2007; Hesterberg et al., 1999; Sato et al., 2005). This thermodynamic stability generally increases as follows: DCPD $<$ DCPA $<$ ACP $\approx \mathrm{TCP}<\mathrm{OCP}<\mathrm{HAP}<$ FAP (e.g. Sato et al., 2005). In agreement with these observations, all shoulders for averaged spectra of crystalline HAP, FAP, CFAP, CHAP, $\beta$-TCP and OCP were relatively well-defined. Apart from the missing post-edge shoulder for DCPA and MCP, amorphous calcium phosphate (Fig. 4) and most but not all DCPD specimens (Fig. 3) showed subtle shoulders. Therefore, more soluble species actually tend to exhibit less pronounced shoulders although a more consistent trend was mainly impaired by three spectra for DCPD, which contained well defined shoulders. Besides these spectra, white-line peaks of few DCPA samples also had clearly visible post-edge shoulders. However, these were near the base of white-line peaks and therefore significantly lower than for all other spectra (Fig. 3). As both poorly crystalline apatite (Fig. 2b) and ACP (Fig. 4) exhibited less pronounced shoulders, this spectral feature might be partly affected by the degree of crystallinity. As the shoulder width of HAP and OCP was larger in comparison to DCPD and DCPA, Brandes et al. (2007) hypothesized that the width 


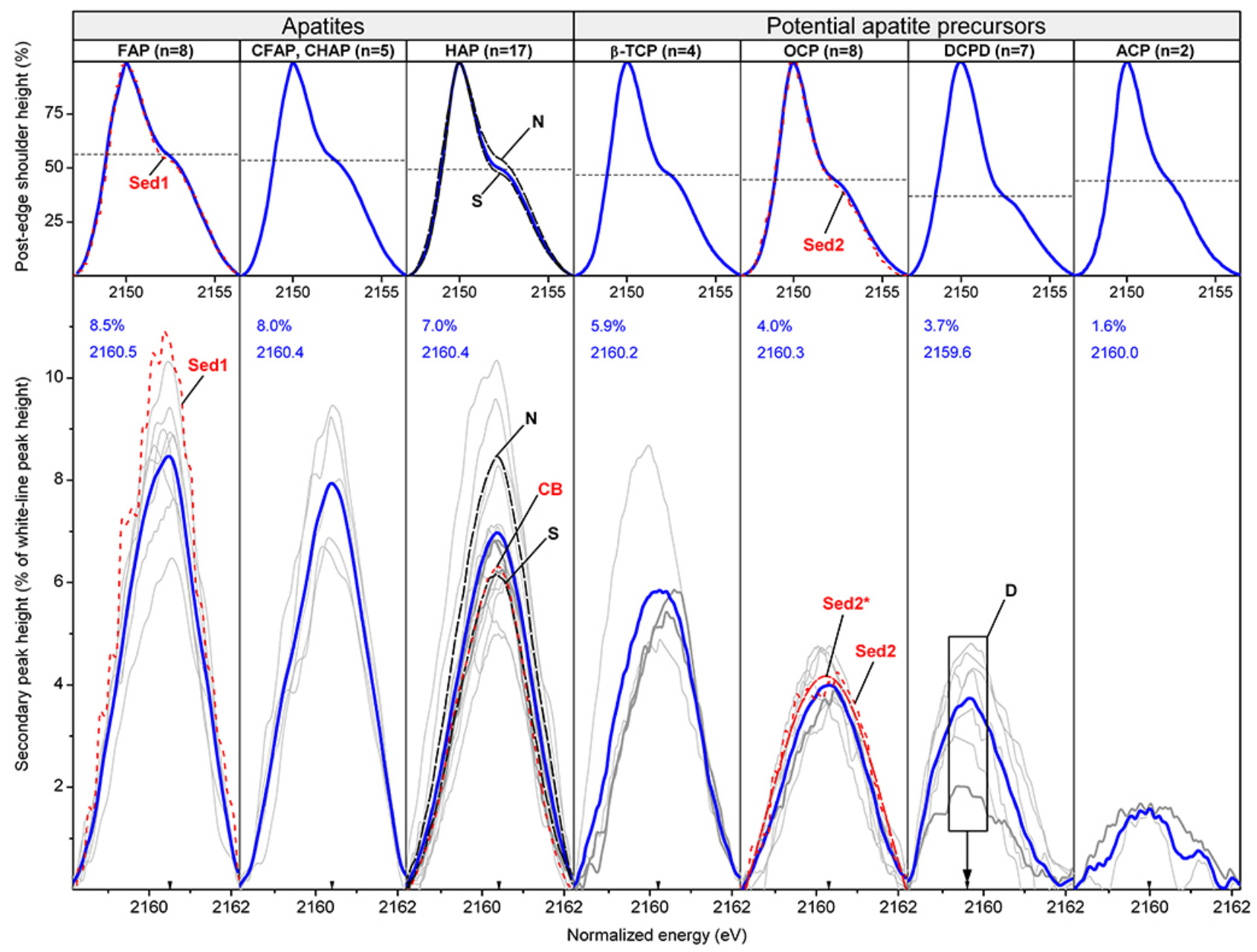

Fig. 4. Secondary peak heights and post-edge shoulder heights in percentages of white-line peak heights for P K-edge XANES spectra of different Ca-P species. Peak-height percentages of $\mu$ XANES data of sediment particles (Brandes et al., 2007) indicate apatite (Sed1) and OCP (Sed2). The apparent OCP peak is different from DCPD due to its different peak position as indicated by a Gaussian Fit (Sed2*; cf. position with D). Individual spectra collected in fluorescence yield and total electron yield mode are shown for secondary peaks by thin and thick grey lines, respectively. Thick blue lines indicate averages for multiple standard curves $(n)$, for which average secondary peak-height percentages and average secondary peak positions $(\mathrm{eV})$ are indicated. Multiple natural $(\mathrm{N}$; average of five spectra) and synthetic $(\mathrm{S}$; average of eight spectra) HAP specimens contribute to the total average of the secondary HAP peak $(n=17$; precise source of four HAP specimens unknown). Secondary peaks of averaged spectra for six calcined bone apatites (CB; not included in the total HAP average) and synthetic HAP (S) match almost perfectly. FAP: fluorapatite; CFAP: carbonate fluorapatite; CHAP: carbonate hydroxylapatite; HAP: hydroxylapatite; $\beta$-TCP: $\beta$-tricalcium phosphate; OCP: octacalcium phosphate; DCPD: dicalcium phosphate dihydrate or brushite; ACP: amorphous calcium phosphate.

may depend on the coordination number. However, a comparison of the averaged spectra clearly showed that, on average, all apatite species exhibited both higher secondary peak heights and higher post-edge shoulder positions than potential apatite precursor phases (Fig. 4). Hence, several spectral features of $\mathrm{Ca}-\mathrm{P}$ species are related to the crystallinity, coordination number and thermodynamic stability. For example, the relative secondary peak height was larger for species with higher thermodynamic stability. Averaged relative secondary peak heights were larger for FAP, CFAP/CHAP, HAP (syn- thetic, natural and poorly crystalline), TCP and OCP than for DCPD, DCPA/MCP and ACP (Table 2).

In summary, these results show that the normalization method developed allows for a high degree of differentiation among Ca-P species although this had previously been thought not to be achievable by P K-edge XANES due to striking spectral similarities (see, e.g., the problematic differentiation between HAP and OCP mentioned by Eveborn et al., 2009). Significance levels for the difference in speciesspecific secondary peak heights are reported on the righthand side of Table 2, and other spectral features provide 
Table 2. Summary of diagnostic P K-edge XANES features for various Ca-P species.

\begin{tabular}{|c|c|c|c|c|c|c|c|c|c|c|c|c|c|c|c|c|c|}
\hline \multirow[b]{2}{*}{$\begin{array}{l}\text { Ca-P } \\
\text { species }\end{array}$} & \multicolumn{3}{|c|}{ Other distinctive features } & \multirow{2}{*}{\multicolumn{2}{|c|}{$\begin{array}{l}\text { Secondary } \\
\text { peak } \\
\text { height }^{1} \\
\%(n)\end{array}$}} & \multirow[b]{2}{*}{ SD } & \multirow[b]{2}{*}{$\begin{array}{l}\text { CFAP } \\
\text { CHAP }\end{array}$} & \multicolumn{5}{|c|}{ Secondary peak height $(\%)$} & \multirow[b]{2}{*}{ DCPD } & \multirow[b]{2}{*}{$\begin{array}{r}\text { DCPA } \\
\text { MCP }\end{array}$} & \multirow[b]{2}{*}{$\mathrm{ACP}$} & \multirow[b]{2}{*}{$\begin{array}{r}\mathrm{P} \text { on } \\
\mathrm{CaCO}_{3}\end{array}$} & \multirow[b]{2}{*}{$\begin{array}{r}\text { HAP } \\
\text { p. cryst } \\
+ \text { am }\end{array}$} \\
\hline & $\begin{array}{l}\text { Post- } \\
\text { edge } \\
\text { shoulder }\end{array}$ & $\begin{array}{l}\text { Post- } \\
\text { edge } \\
\text { shoulder } \\
\text { height }\end{array}$ & $\begin{array}{l}\text { Oxygen } \\
\text { osc. }\end{array}$ & & & & & $\stackrel{\text { HAP }}{\sum}$ & $\begin{array}{l}\text { HAP } \\
\text { synth. }\end{array}$ & $\begin{array}{r}\text { HAP } \\
\text { nat. }\end{array}$ & $\mathrm{TCP}$ & $\mathrm{OCP}$ & & & & & \\
\hline FAP & broad & very high & narrow & $\begin{array}{l}8.7 \\
(8)\end{array}$ & 8.5 & 1.1 & $\mathrm{~N}$ & ** & $* * *$ & $\mathrm{~N}$ & $*$ & $* * * *$ & $* * * *$ & $* * * *$ & $* * * *$ & $* * *$ & $* * *$ \\
\hline $\begin{array}{l}\text { CFAP } \\
\text { CHAP }\end{array}$ & broad & very high & narrow & $\begin{array}{l}8.1 \\
(5)\end{array}$ & 8.0 & 1.3 & & $\mathrm{~N}$ & $* *$ & $\mathrm{~N}$ & $\mathrm{~N}$ & $* * * *$ & $* * * *$ & $* * *$ & $* *$ & $* *$ & ** \\
\hline $\begin{array}{l}\text { HAP } \\
\sum\end{array}$ & broad & high & narrow & $\begin{array}{l}7.1 \\
(17)\end{array}$ & 7.0 & 1.4 & & & $\mathrm{~N}$ & $\mathrm{~N}$ & $\mathrm{~N}$ & $* * * *$ & $* * * *$ & $* * * *$ & $* * * *$ & $* * *$ & $* *$ \\
\hline $\begin{array}{l}\text { HAP } \\
\text { synth. }\end{array}$ & broad & high & narrow & $\begin{array}{l}6.6 \\
(7)\end{array}$ & 6.3 & 0.7 & & & & ** & $\mathrm{N}$ & $* *$ & $* * * *$ & $* * * *$ & $* * * *$ & $* *$ & $* * *$ \\
\hline $\begin{array}{l}\text { HAP } \\
\text { nat. }\end{array}$ & broad & high & narrow & $\begin{array}{l}8.6 \\
(5)\end{array}$ & 8.5 & 1.3 & & & & & $\mathrm{~N}$ & $* * * *$ & $* * *$ & $* * *$ & $* *$ & $* *$ & * \\
\hline ß-ТCP & broad & medium & medium & $\begin{array}{l}6.3 \\
(4)\end{array}$ & 5.9 & 1.6 & & & & & & $* *$ & $*$ & $*$ & $*$ & $\mathrm{~N}$ & $\mathrm{~N}$ \\
\hline OCP & broad & medium & narrow & $\begin{array}{l}4.2 \\
(8)\end{array}$ & 4.0 & 0.5 & & & & & & & $N \sqrt{ }$ & $\mathrm{N} \sqrt{ }$ & $* * * *$ & $*$ & $\mathrm{~N} \sqrt{ }$ \\
\hline DCPD & mixed & low & medium & $\begin{array}{l}3.8 \\
(7)^{2}\end{array}$ & 3.7 & 1.0 & & & & & & & & $\mathrm{~N} \sqrt{ } ?$ & $*$ & $\mathrm{~N} \sqrt{ } ?$ & $\mathrm{~N} \sqrt{ }$ ? \\
\hline $\begin{array}{l}\text { DCPA } \\
\text { MCP }\end{array}$ & missing & $\mathrm{n} / \mathrm{a}$ & broad & $\begin{array}{l}2.6 \\
(16)^{3}\end{array}$ & 2.5 & 2.8 & & & & & & & & & $\mathrm{~N} \sqrt{ }$ & $\mathrm{N}$ & $\mathrm{N}$ \\
\hline $\mathrm{ACP}$ & narrow & medium & broad & $\begin{array}{l}1.6 \\
(2)\end{array}$ & 1.6 & 0.1 & & & & & & & & & & $\mathrm{~N}$ & $* *$ \\
\hline $\begin{array}{l}\mathrm{P} \text { on } \\
\mathrm{CaCO}_{3}\end{array}$ & mixed & low & broad & $\begin{array}{l}2.4 \\
(2)\end{array}$ & 2.4 & 1.5 & & & & & & & & & & & $\mathrm{~N}$ \\
\hline $\begin{array}{l}\text { HAP } \\
\text { p. cryst. }\end{array}$ & narrow & low & broad & $\begin{array}{l}4.2 \\
(1)\end{array}$ & $\mathrm{n} / \mathrm{a}$ & $\mathrm{n} / \mathrm{a}$ & & & & & & & & & & & \\
\hline $\begin{array}{l}\text { HAP } \\
\text { am. }\end{array}$ & broad & low & narrow & $\begin{array}{l}3.8 \\
(1)^{2}\end{array}$ & $\mathrm{n} / \mathrm{a}$ & $\mathrm{n} / \mathrm{a}$ & & & & & & & & & & & \\
\hline
\end{tabular}

${ }^{1}$ Averaged relative secondary peak height (\% of white-line peak height). Left column: averaged secondary peak height $(\%)$ of individual spectra and number of averaged spectra in parentheses. Right column: secondary peak height (\%) of model spectra (averages for multiple curves; Fig. 4)

${ }^{2}$ Secondary peak shifted towards main peak.

${ }^{3}$ Includes four spectra, which lacked a secondary peak (see high standard deviation).

$\mathrm{N}$ : difference of secondary peak heights (\%; population means) is non-significant (two-sample independent $t$ test)

$*$ : difference of secondary peak heights $(\%)$ is significant at the 0.05 level

$* *$ : difference of secondary peak heights $(\%)$ is significant at the 0.01 level

***: difference of secondary peak heights $(\%)$ is significant at the 0.001 level

$* * * *$ : difference of secondary peak heights $(\%)$ is significant at the 0.0001 level

$\mathrm{N} \sqrt{ }$ : denotes other distinctive features for two species which cannot be distinguished by their secondary peak heights (note that other distinctive features are not denoted for pairs with significantly different secondary peak

$\mathrm{N} \sqrt{ }$ : denotes other distinctive features for two species which cannot be distinguished by their secondary peak heights (note that other distinctive features are not denoted for pairs with significantly different secondary peasters
heights). OCP distinguishable from DCPD (secondary peak shift or missing post-edge shoulder), DCPA (missing post-edge shoulder), MCP (missing post-edge shoulder), poorly crystalline HAP (missing post-edge
shoulder, broad oxygen oscillation) and amorphous HAP (secondary peak shift). ACP distinguishable from DCPD/MCP (missing post-edge shoulder).

shoulder, broad oxygen oscillation) and amorphous HAP (secondary peak shift). ACP distinguishable from DCPD/MCP (missing post-edge shoulder).
$\mathrm{N} \sqrt{ }$ ?: denotes other potentially distinctive features for two species which cannot be distinguished by their secondary peak heights. DCPD likely (note the two atypical DCPDs in Fig. 3) distinguishable from DCPA (absent $\mathrm{N} \sqrt{ }$ ?: denotes other potentially distinctive features for two species which cannot be distinguished by their secondary peak heights. DCPD likely (note
secondary peak shift), $\mathrm{P}$ on $\mathrm{CaCO}_{3}$ (absent secondary peak shift, broad oxygen oscillation) and poorly crystalline HAP (absent secondary peak shift).

secondary peak shift), $\mathrm{P}$ on $\mathrm{CaCO}_{3}$ (absent secondary peak shift, broad oxygen oscillation) and poorly crystalline $\mathrm{HAP}$ (absent secondary peak shift).
Note that $\mathrm{P}$ on $\mathrm{CaCO}_{3}$ was probably contaminated by crystalline Ca-P phases (see text) and that poorly crystalline HAP and amorphous HAP require further verification by additional spectra.

Abbreviations: n/a (not applicable); SD (standard deviation); oxygen osc. (oxygen oscillation); HAP synth. (synthetic HAP); HAP nat. (natural HAP); HAP p. cryst. (poorly crystalline HAP); HAP am. (amorphous HAP).

additional discrimination between species (Table 2). This degree of differentiation is achieved despite measurement deviations among different spectral libraries. In general, withinstudy differences between spectral features of two species were more pronounced than could be assumed from the peak intensity ranges shown in Figs. 3 and 4. For example, the plots for HAP and OCP show a relatively small difference between the lowest secondary peak for HAP and the highest peak for OCP. However, these two spectra were not pairwise (collected in the same study) spectra. Each of the eight studies which collected an OCP spectrum also provided an HAP spectrum (see reference numbers in Fig. 3) and corresponding discrepancies in secondary peak heights between these two species were relatively large.

\subsection{Speciation examples}

To exemplify the applicability of this novel method for identification of individual Ca-P species in complex matrices, spectra of bone apatites (Rajendran, 2011; Rajendran et al., 2013) and sediment particles (Brandes et al., 2007) were also examined. Rajendran et al. (2011, 2013) investigated dried and calcined bones with XANES and observed that the spectra changed by heating dried bones to 600 or $800^{\circ} \mathrm{C}$. Spectra of those calcined bone apatites were post-processed (normalized, baseline-subtracted and averaged) in the same way as other reference compounds (Fig. 4, CB, $n=6$ ). The spectrum thus obtained was compared with averaged spectra for eight synthetic (Fig. 4, S) and five natural HAP (Fig. 4, N) specimens. This comparison showed that increased temperatures obviously generated relatively pure hydroxylapatites because the secondary peak of the averaged calcined bone apatite spectrum matched that of synthetic HAP exactly. The 
five natural HAP specimens of the compiled library exhibited higher secondary peaks than synthetic HAP or calcined bones, which could be a consequence of various impurities, such as fluoride substitutions. The HAP sample from Snarum (Norway; Brandes et al., 2007) was the only natural HAP that matched the secondary peak of synthetic HAP well (cf. synthetic HAP and HAP-1 in Fig. S2 in the Supplement). Hence, the selection of natural vs. synthetic HAP reference materials appears to be important for commonly used quantitative XANES approaches, such as least-squares linear combination fitting.

Further, Rajendran et al. (2013) speculated that dried bone probably contained HAP and $\beta$-TCP. Indeed dried bone apatite (Fig. S2 in the Supplement) showed a much lower secondary peak than synthetic HAP, which could theoretically indicate the presence of more soluble precursor phases. For instance, all secondary peaks of dried bone apatite were even smaller than those of OCP. However, the secondary peak height of dried bone was also comparable to that of poorly crystalline HAP. From a closer observation of the entire spectrum it may be deduced that dried bone actually consisted of poorly crystalline apatite because both of these had relatively broad oxygen oscillations (Fig. 2b). This assumption would be in line with the conclusion of Rey et al. (2009), who inferred from a thorough review of several studies that no substantial evidence has been established for the presence of any Ca-P phase in bone except for poorly crystalline apatite. As it was not possible to unequivocally identify more soluble precursor phases in bone, apatite may form only by direct nucleation in bone.

Interestingly, this direct nucleation in bone is opposed to the well-documented apatite formation by precursor phases in sediment (Gunnars et al., 2004; Jahnke et al., 1983; Krajewski et al., 1994; Oxmann and Schwendenmann, 2014; Schenau et al., 2000; Van Cappellen and Berner, 1988; see also Morse and Casey (1988) and Nancollas et al. (1989) for the Ostwald step rule of successive crystallization; note also the significant apparent OCP levels in high $\mathrm{pH}$ substrates determined, e.g., by Beauchemin et al. (2003) using linear combination fitting of XANES spectra). This precursor pathway for the formation of authigenic CFAP, which appears likely, is also substantiated by the second example of the applicability of the proposed method. Post-processing of $\mu$ XANES spectra from two sedimentary Ca-P particles (Brandes et al., 2007) revealed that the secondary peak height of one particle was comparable to that of FAP (Fig. 4, Sed1), whereas the secondary peak of the other particle very closely matched the averaged secondary peak of OCP (Fig. 4, Sed2 and Sed2*). That the latter particle most likely comprised OCP was also confirmed by all other important spectral features, such as a missing shift of the secondary peak for exclusion of DCPD (Fig. 4, D), an OCP-typical shoulder height and a broader shoulder feature. Finally, the spectrum exhibited a well-separated oxygen oscillation that rules out $\mathrm{P}$ adsorbed on $\mathrm{CaCO}_{3}$ and poorly crystalline apatite. In view of the two different $\mu$ XANES spectra, Brandes et al. (2007) suggested that X-ray fluorescence spectroscopy may offer a good opportunity to approach the subject of the very early formation stages of authigenic CFAP with a novel technique. The formation of CFAP-bearing phosphorite deposits, for instance, still remains controversial after several decades of intense research (e.g. Bentor, 1980; Sheldon, 1981; Tribble et al., 1995). Brandes et al. (2007) further concluded that a suite of appropriate reference materials will be required to tackle these issues by XANES. By considering $81 \mathrm{Ca}-\mathrm{P}$ reference materials of 17 spectral libraries, this study provides evidence that $\mathrm{P}$ K-edge XANES is indeed excellently suited for investigations on apatite formation. This study also provides evidence that authigenic apatite formation proceeds most likely via an OCP precursor pathway, in addition to direct nucleation. The numerous controls on the two pathways in sediment can be summed up by the terms "saturation state" (e.g. supersaturation with respect to CFAP or precursors; Atlas, 1975; Gunnars et al., 2004; Van Cappellen and Berner, 1991), "kinetic factors" (Atlas and Pytkowicz, 1977; Gulbrandsen et al., 1983; Gunnars et al., 2004, Jahnke et al., 1983; Schenau et al., 2000; Sheldon, 1981) and "inhibitors" (Eanes and Rattner, 1981; Golubev et al., 1999; Gunnars et al., 2004; Martens and Harriss, 1970; Van Cappellen and Berner, 1991). In consideration of the still limited knowledge about the complex interplay of these factors in CFAP formation, Slomp (2011) recently emphasized the need for detailed studies on this subject.

\subsection{Limitations, possible sources of error and recommendations}

Based on the relatively large number of naturally occurring $\mathrm{Ca}-\mathrm{P}$ species, numerous identifying features are required to obtain adequate analyte specificity. The spectral breakdown presented considered a representative set of the most abundant Ca-P species in environmental and biological matrices and should therefore be well suited for studies in different fields. Constraints due to the presence of $\mathrm{P}$ species other than those of Ca-P appear to be insignificant because features of $\mathrm{Ca}-\mathrm{P}$ at the $\mathrm{P}$ K-edge were found to be distinctive. For instance, spectra of Ca-P are easily distinguishable from those of potassium phosphates, aluminium phosphates, iron phosphates and organic $\mathrm{P}$ compounds (e.g. Brandes et al., 2007; Giguet-Covex et al., 2013; Sato et al., 2005).

Further, self-absorption effects impair the identification of species by XANES. However, using diluted or finely ground and thinly mounted samples during FY measurements appears to efficiently mitigate these effects because species-specific features were comparable for TEY and FY spectra (see thin and thick grey lines in Fig. 4). Spectral distortions due to self-absorption attenuate especially lowenergy regions of the spectral range investigated (Tannazi and Bunker, 2005). However, the use of peak-height ratios is obviously advantageous precisely because self-absorption 
may attenuate not only main but also other peaks. Significant linear correlations between main and secondary peak heights for edge-jump-normalized spectra of certain species $(p<$ 0.0001; Fig. 1c) clearly demonstrated that a consideration of peak-height ratios was crucial for distinguishing between spectra of different species. However, this differentiation was more reliable for spectra with intense peaks (Fig. 1c), suggesting that self-absorption should be efficiently mitigated. Known effects of inappropriate particle sizes may also influence peak-height ratios and should therefore be considered during measurements.

Quantitative estimates by bulk XANES measurements require thorough analysis because spectral features of different species overlap (Beauchemin et al., 2003; Doolette and Smernik, 2011). However, due to the poor resolution of bulk XANES analyses in complex matrices even a qualitative detection may not be feasible, e.g. if the species of interest is a minor component. In this case $\mu$ XANES analysis, which also allows for $\mathrm{X}$-ray fluorescence mapping of $\mathrm{P}$ and other elements at a sub-micron spatial resolution (Brandes et al., 2007; Diaz et al., 2008), appears to be the instrumental method of choice.

The spectral analysis presented in this study also provides recommendations for standard selection and synthesis. For example, only few spectra were available for $\mathrm{Ca}-\mathrm{P}$ compounds that exhibited relatively broad oxygen oscillations. These spectra included $\mathrm{P}$ adsorbed on $\mathrm{CaCO}_{3}$ and amorphous or poorly crystalline phases, such as ACP or poorly crystalline apatite. Precisely those reference compounds tended to be more unreliable due to co-precipitation. Therefore, these compounds should be additionally verified by other analytical methods or acquired from sources that provide a corresponding product certification.

\section{Conclusions}

In this study, a novel normalization method was developed, which, for the first time, allowed for a systematic comparison of P K-edge XANES spectra of a compiled library, and which facilitated the identification of important diagnostic spectral Ca-P features in this library. The compiled library included 81 spectra of various Ca-P species from 17 libraries. The normalization method considered relative energy ranges between peaks, and peak-height ratios between main and secondary peaks. It was found that relative post-edge shoulder heights and relative secondary peak heights provide essential identifying features in addition to the previously reported criterion of a pronounced post-edge shoulder. These relative heights were crucial for improved analyte specificity, specifically because they provided a set of distinctive features (e.g. distinctive species-specific peak intensity ranges). A spectral breakdown is given in Table 2 in order to summarize determined diagnostic features. From this follows that P K-edge XANES is excellently suited for environmental and biolog- ical research on Ca-P and that the method developed allows for a high degree of differentiation among Ca-P species.

Important applications for the method were demonstrated by two examples: (i) application of the method to bone apatite spectra confirmed that bone material likely comprises only poorly crystalline apatite, which confirms direct nucleation of apatite in bone. This direct nucleation in bone is apparently opposed to the well-documented authigenic apatite formation by precursor phases in sediment. (ii) Application of the method to $\mu$ XANES spectra of sediment particles provided evidence for the occurrence of OCP in sediment and therefore for the probability of apatite formation by successive crystallization according to the Ostwald step rule. Finally, the method presented also revealed that reference materials were occasionally inconsistent or incorrectly assigned due to apparent contamination. Hence, this study also offered a basis for standard selection and appropriate standard syntheses.

\section{Supplementary material related to this article is available online at http://www.biogeosciences.net/11/ 2169/2014/bg-11-2169-2014-supplement.zip.}

Acknowledgements. I thank Luitgard Schwendenmann (The University of Auckland; School of Environment) for valuable comments on an earlier version of the manuscript. Thanks also to Peter Kraal (Utrecht University; Faculty of Geosciences) and an anonymous referee for constructive and helpful comments during the review process. This study was funded by the German Research Foundation through a research fellowship granted to J. F. Oxmann under the code OX 54/2-1.

The service charges for this open access publication have been covered by a Research Centre of the Helmholtz Association.

Edited by: J. Middelburg

\section{References}

Ajiboye, B., Akinremi, O. O., Hu, Y., and Flaten, D. N.: Phosphorus speciation of sequential extracts of organic amendments using nuclear magnetic resonance and X-ray absorption nearedge structure spectroscopies, J. Environ. Qual., 36, 1563-1576, 2007a.

Ajiboye, B., Akinremi, O. O., and Jürgensen, A.: Experimental validation of quantitative XANES analysis for phosphorus speciation, Soil Sci. Soc. Am. J., 71, 1288-1291, 2007b.

Ajiboye, B., Akinremi, O. O., Hu, Y., and Jürgensen, A.: XANES speciation of phosphorus in organically amended and fertilized vertisol and mollisol, Soil Sci. Soc. Am. J., 72, 1256-1262, 2008.

Atlas, E. L.: Phosphate equilibria in seawater and interstitial waters, Ph.D. thesis, Oregon State University, Corvallis, 1975. 
Atlas, E. L. and Pytkowicz, R. M.: Solubility behavior of apatites in seawater, Limnol. Oceanogr., 22, 290-300, 1977.

Ban, S., Matsuura, M., Arimoto, N., Hayashizaki, J., Itoh, Y., and Hasegawa, J.: Factors affecting the transformation of octacalcium phosphate to apatite in vitro, Dent. Mater. J., 12, 106-117, 1993.

Baturin, G. N.: Principal features of the marine geochemistry of disseminated phosphorus, in: Developments in Sedimentology, edited by: Baturin, G. N., Elsevier B. V., 343 pp., 1981.

Beauchemin, S., Hesterberg, D., Chou, J., Beauchemin, M., Simard, R. R., and Sayers, D. E.: Speciation of phosphorus in phosphorus-enriched agricultural soils using X-ray absorption near-edge structure spectroscopy and chemical fractionation, J. Environ. Qual., 32, 1809-1819, 2003.

Bentor, Y. K.: Phophorites: the unsolved problems, in: Marine Phosphorites: Geochemistry, Occurence, Genesis, edited by: Bentor, Y. K., SEPM (Society for Sediment Geology), Tulsa, 247, 3-18, 1980.

Brandes, J. A., Ingall, E., and Paterson, D.: Characterization of minerals and organic phosphorus species in marine sediments using soft X-ray fluorescence spectromicroscopy, Mar. Chem., 103, 250-265, 2007.

Christoffersen, M. R., Christoffersen, J., and Kibalczyc, W.: Apparent solubilities of 2 amorphous calcium phosphates and of octacalcium phosphate in the temperature-range $30-42^{\circ} \mathrm{C}$, J. Cryst. Growth, 106, 349-354, 1990.

Diaz, J., Ingall, E., Benitez-Nelson, C., Paterson, D., de Jonge, M. D., McNulty, I., and Brandes, J. A.: Marine polyphosphate: A key player in geologic phosphorus sequestration, Science, 320, 652-655, 2008.

Doolette, A. L. and Smernik, R. J.: Soil organic phosphorus speciation using spectroscopic techniques, in: Phosphorus in Action: Biological Processes in Soil Phosphorus Cycling. Soil Biology Series 26, edited by: Bünemann, E. K., Oberson, A., Frossard, E., Springer, Berlin, Heidelberg, 3-36, 2011.

Eanes, E. D. and Rattner, S. L.: The effect of magnesium on apatite formation in seeded supersaturated solutions at $\mathrm{pH}$ 7.4, J. Dent. Res., 60, 1719-1723, 1981.

Eveborn, D., Gustafsson, J. P., Hesterberg, D., and Hillier, S.: XANES speciation of $\mathrm{P}$ in environmental samples: an assessment of filter media for on-site wastewater treatment, Environ. Sci. Tech., 43, 6515-6521, 2009.

Giguet-Covex, C., Poulenard, J., Chalmin, E., Amoud, F., Rivard, C., Jenny, J.-P., and Dorioz, J. M.: XANES spectroscopy as a tool to trace phosphorus transformation during soil genesis and mountain ecosystem development from lake sediments, Geochim. Cosmochim. Ac., 118, 8244, doi:10.1016/j.gca.2013.04.017, 2013.

Golubev, S. V., Pokrovsky, O. S., and Savenko, V. S.: Unseeded precipitation of calcium and magnesium phosphates from modified seawater solutions, J. Cryst. Growth, 205, 354-360, 1999.

Gulbrandsen, R. A., Roberson, C. E., and Neil, S. T.: Time and the crystallization of apatite in seawater, Geochim. Cosmochim. Ac., 48, 213-218, 1983.

Güngör, K., Jürgensen, A., and Karthikeyan, K. G.: Determination of phosphorus speciation in dairy manure using XRD and XANES spectroscopy, J. Environ. Qual., 36, 1856-1863, 2007.
Gunnars, A., Blomqvist, S., and Martinsson, C.: Inorganic formation of apatite in brackish seawater from the Baltic Sea: an experimental approach, Mar. Chem., 91, 15-26, 2004.

Hesterberg, D., Zhou, W., Hutchison, K. J., Beauchemin, S., and Sayers, D. E.: XAFS study of adsorbed and mineral forms of phosphate, J. Synchrotron Rad., 6, 636-638, 1999.

Ingall, E. D., Brandes, J. A., Diaz, J. M., de Jonge, M. D., Paterson, D., McNulty, I., Elliott, W. C., and Northrup, P.: Phosphorus Kedge XANES spectroscopy of mineral standards, J. Synchrotron Rad., 18, 189-197, 2011.

Jahnke, R. A., Emerson, S. R., Roe, K. K., and Burnett, W. C.: The present day formation of apatite in Mexican continental margin sediments, Geochim. Cosmochim. Ac., 47, 259-266, 1983.

Kizewski, F., Liu, Y.-T., Morris, A., and Hesterberg, D.: Spectroscopic approaches for phosphorus speciation in soils and other environmental systems, J. Environ. Qual., 40, 751-766, 2011.

Krajewski, K. P., Van Cappellen, P., Trichet, J., Kuhn, O., Lucas, J., Martinalgarra, A., Prevot, L., Tewari, V. C., Gaspar, L., Knight, R. I., and Lamboy, M.: Biological processes and apatite formation in sedimentary environments, Eclog. Geol. Helvet., 87, 701745,1994

Kruse, J. and Leinweber, P.: Phosphorus in sequentially extracted fen peat soils: a K-edge X-ray absorption near-edge structure (XANES) spectroscopy study, J. Plant Nutr. Soil Sci., 171, 613620, 2008

Kruse, J., Negassa, W., Appathurai, N., Zuin, L., and Leinweber, P.: Phosphorus speciation in sequentially extracted agro-industrial by-products: Evidence from X-ray absorption near edge structure spectroscopy, J. Environ. Qual., 39, 2179-2184, 2010.

Lombi, E., Scheckel, K. G., Armstrong, D., Forrester, S., Cutler, J. N., and Paterson, D.: Speciation and distribution of phosphorus in a fertilized soil: a synchrotron-based investigation, Soil Sci. Soc. Am. J., 70, 2038-2048, 2006.

Martens, C. S. and Harriss, R. C.: Inhibition of apatite precipitation in the marine environment by magnesium ions, Geochim. Cosmochim. Ac., 84, 621-625, 1970.

Morse, J. W. and Casey, W. H.: Ostwald processes and mineral paragenesis in sediments, Am. J. Sci., 288, 537-560, 1988.

Nancollas, G. H., LoRe, M., Perez, L., Richardson, C., and Zawacki, S. J.: Mineral phases of calcium phosphate, Anat. Rec., 224, 234 241, 1989

Newville, M.: Fundamentals of XAFS revision 1.7, Consortium for Advanced Radiation Sources, University of Chicago, Chicago, 2004.

Oxmann, J. F. and Schwendenmann, L.: Quantification of octacalcium phosphate, authigenic apatite and detrital apatite in coastal sediments using differential dissolution and standard addition, Ocean Sci. Discuss., 11, 293-329, 2014, http://www.ocean-sci-discuss.net/11/293/2014/.

Peak, D., Sims, J. T., and Sparks, D. L.: Solid-state speciation of natural and alum-amended poultry litter using XANES spectroscopy, Environ. Sci. Tech., 36, 4253-4261, 2002.

Rajendran, J.: XANES and FTIR study on dried and calcined bones, M.S. thesis, The University of Texas at Arlington, 98 pp., 2011.

Rajendran, J., Gialanella, S., and Aswath, P.: XANES analysis of dried and calcined bones, Mater. Sci. Eng. C, 33, MSC-04059, doi:10.1016/j.msec.2013.05.038, 2013. 
Rey, C., Combes, C., Drouet, C., and Glimcher, M. J.: Bone mineral: update on chemical composition and structure, Osteoporosis Int., 20, 1013-1021, 2009.

Ruttenberg, K. C.: Development of a sequential extraction method for different forms of phosphorus in marine sediments, Limnol. Oceanogr., 37, 1460-1482, 1992.

Ruttenberg, K. C. and Berner, R. A.: Authigenic apatite formation and burial in sediments from non-upwelling continental margin environments, Geochim. Cosmochim. Ac., 57, 991-1007, 1993.

Sato, S., Solomon, D., Hyland, C., Ketterings, Q. M., and Lehmann, J.: Phosphorus speciation in manure and manure-amended soils using XANES spectroscopy, Environ. Sci. Tech., 39, 7485-7491, 2005.

Schenau, S. J. and De Lange, G. J.: A novel chemical method to quantify fish debris in marine sediments, Limnol. Oceanogr., 45, 963-971, 2000.

Schenau, S. J., Slomp, C. P., and De Lange, G. J.: Phosphogenesis and active phosphorite formation in sediments from the Arabian Sea oxygen minimum zone, Mar. Geol., 169, 1-20, 2000.

Seiter, J. M., Staats-Borda, K. E., Ginder-Vogel, M., and Sparks, D. L.: XANES spectroscopic analysis of phosphorus speciation in alum-amended poultry litter, J. Environ. Qual., 37, 477-485, 2008.

Sheldon, R. P.: Ancient marine phosphorites, Annu. Rev. Earth Pl. Sc., 9, 251-284, 1981.

Shober, A. L., Hesterberg, D., Sims, J. T., and Gardner, S.: Characterization of phosphorus species in biosolids and manures using XANES spectroscopy, J. Environ. Qual., 35, 1983-1993, 2006.
Slomp, C. P.: Phosphorus cycling in the estuarine and coastal zones: Sources, sinks, and Transformations, in: Treatise on estuarine and coastal science, Vol. 5, edited by: Wolanski, E., McLusky, D. S., Academic Press, Waltham, 201-229, 2011.

Tannazi, F. and Bunker, G.: Determination of chemical speciation by XAFS, Phys. Scripta, 115, 953-956, 2005.

Toor, G. S., Peak, D., and Sims, J. T.: Phosphorus speciation in broiler litter and turkey manure produced from modified diets, J. Environ. Qual., 34, 687-697, 2005.

Toor, G. S., Hunger, S., Peak, D., Sims, J. T., and Sparks, D. L.: Advances in the characterization of phosphorus in organic wastes: Environmental and agronomic applications, Adv. Agron., 89, 1$72,2006$.

Tribble, J. S., Arvidson, R. S., Lane III, M., and Mackenzie, F. T.: Crystal chemistry, and thermodynamic and kinetic properties of calcite, dolomite, apatite, and biogenic silica: applications to petrologic problems, Sediment. Geol., 95, 11-37, 1995.

Van Cappellen, P. and Berner, R. A.: Fluorapatite crystal growth from modified seawater solutions, Geochim. Cosmochim. Ac., 55, 1219-1234, 1991.

Van Cappellen, P. and Berner, R. A.: A mathematical model for the early diagenesis of phosphorus and fluorine in marine sediments; apatite precipitation, Am. J. Sci., 288, 289-333, 1988. 